\title{
Am I STEM? Broadening Participation by Transforming Students' Perceptions of Self and Others as STEM-Capable
}

\author{
Amanda Blakewood Pascale \\ University of North Florida \\ Dan Richard
University of North Florida \\ Karthikeyan Umapathy \\ University of North Florida
}

To meet the needs of the 21st century, the science, technology, engineering, and mathematics (STEM) workforce will require universities to produce STEM-capable individuals who STEM identify, and who feel STEM connected. However, higher education institutions tend to operate in disciplinary silos; only those in STEM disciplines are tasked with sourcing solutions for complex STEM problems. In this study, the authors explore how participation in an integrative STEM internship experience (Data Science for Social Good) transforms students from different disciplinary backgrounds' STEM identity. Findings reveal that STEM and non-STEM students undergo shifts in perspectives regarding themselves and others as STEMcapable. Implications and recommendations are discussed.

Keywords: STEM, identity, experiential learning, higher education, integrated learning, interdisciplinary

\section{INTRODUCTION}

A 2018 Deloitte study indicates that the U.S. manufacturing sector will add 4.6 million jobs by 2028 , yet likely only 2.2 million of those positions will be filled (Giffi et al., 2018). Thus, it is predicted that in $2028,53 \%$ of manufacturing jobs will go unfilled due to a shortage of skilled workers. Many of these $21^{\text {st }}$ century jobs will require skill sets that are typically attributed to knowledge acquired through preparation in Science, Technology, Engineering, or Math (STEM) disciplines. Thus, over the last several decades, these challenges have spawned increased attention from the United States (U.S.) government, policy and granting agencies, and educators regarding the preparation of the next generation of the STEM workforce (Landivar, 2013). The impending critical call for STEM trained workers, and the associated growing concerns over the lack of diversity in STEM fields, led to the rise of the popular "pipeline" metaphor to describe the problems the U.S. was facing in preparing STEM workers. The STEM pipeline model depicts a one-directional approach to a STEM career. Implicit in this understanding, STEM educators and researchers sought ways to increase the numbers and diversity of individuals in the STEM pipeline, and to find, identify, and mitigate pipeline leaks (Burkham, Lee, \& Smerdon, 1997; Lee \& Burkham, 1992). Newer 
perspectives, however, have pointed out the limitations of the pipeline approach. A recent report from the National Science Foundation (NSF; 2015), titled Revisiting the STEM Workforce challenges previous conceptions of the STEM workforce problem. The report reframes the issue, positing a refocus on producing STEM-capable individuals rather than increasing the numbers in the STEM pipeline. Termed the "pathways approach" (NSF, 2015, p. 15), the NSF's conceptualization allows for a more fluid understanding where individuals have "on-ramps [and] off-ramps" (NSF, 2015, p. 14) to STEM. Indeed, there is evidence to suggest that relegating the STEM workforce problem to a lack of numbers may be shortsighted and oversimplified. For example, Graf, Fry, and Funk (2018) point out that 48\% of STEM graduates do not join the STEM workforce. From a pipeline perspective, this statistic is particularly alarming; nearly half of those who are traditionally educated in STEM disciplines will not utilize their training to contribute to the STEM workforce.

\section{Higher Education and the STEM Workforce}

In the U.S., institutions of higher education are considered largely responsible for the preparation of STEM students to meet workforce demands. Yet, despite calls for change in STEM workforce training, still many colleges and universities operate in disciplinary silos. Even students who are trained in STEM disciplines lack the ability to translate STEM skills into real-world applications (Graf, Fry, \& Funk, 2018; Whitehouse-NSTC, 2018). To effectively meet the needs of the $21^{\text {st }}$ century, STEM workforce preparation models will require interdisciplinary approaches that break through academic silos and encourage real and practical application (Whitehouse-NSTC, 2018). Furthermore, it is incumbent on colleges and universities to provide such experiences. Despite the critical need, interdisciplinary experiential programs are the exception, not the norm, in institutions of higher education. To this end, little is understood about how these types of experiences influence the transformation of collegiates from different disciplinary backgrounds into STEM-capable individuals. This research explores how participation in an interdisciplinary experiential summer internship program, Data Science for Social Good, influences the transformation of students' perspectives of themselves and others as STEM-capable.

\section{Interdisciplinary STEM Learning and Data Science}

Universities are under pressure to boost students' STEM career interest to meet workforce demands. Over the past two decades, STEM careers have been evolving from disciplinary silos to overlapping disciplines and skill sets. Thus, universities should take an interdisciplinary approach for STEM degree programs where academic concepts are connected with real-world applications (Whitehouse-NSTC, 2018). Interdisciplinary STEM programs are expected to satisfy four key tenets of STEM teaching and learning (Mayes, Rittschof, Gallant, \& Martin, 2017):

[i] moving from traditional content silos to interdisciplinary STEM perspective that is incorporating at least two of the four STEM disciplines...[ii] moving from traditional teacher-directed classrooms to authentic learning environments that provide students with opportunities to engage in real-world problem-solving...[iii] establishing professional learning and collaborative community partnerships involving faculty, business, research institute, nonprofit, and government representatives to support the authentic, real-world illstructured problem solving... [and iv] moving beyond student engagement outcomes to developing $21^{\text {st }}$ century STEM reasoning abilities among students.

With the rise of a digitized world where data is changing everything, data science has emerged as one of the critical disciplines to aid our current and future scientific discoveries and innovations (Berman et al., 2018). Data science blends the fields of statistics, mathematics, and computer science to facilitate sensemaking based on a growing and towering amount of data on application domains such as business, medicine, and social science (Ley \& Bordas, 2018). Thus, data science has evolved as an interdisciplinary field that integrates concepts from a variety of disciplines. Given the importance of data-driven approaches 
for research and commerce, universities need to devise training programs to prepare members of the STEM workforce who can use data to solve complex real-world problems (Berman et al., 2018).

\section{Ecological Model of STEM Identity Development}

If students are going to move beyond their disciplinary boundaries to engage with others in interdisciplinary contexts, STEM students will need to have positive and challenging interactions across disciplinary boundaries that affect their identity as an interdisciplinary STEM graduate (c.f., e.g., a Biologist, a Chemist). Identity theory suggests that individuals have a relatively stable sense of self that is built through experience over time, yet social and contextual factors can influence how an individual identifies themselves (Markus \& Kunda, 1986). For a sophisticated, interdisciplinary representation of the self to emerge, an individual must have complex, interdisciplinary experiences across disciplinary boundaries that help provide the social context for the development of the STEM identity.

Bronfenbrenner's (1977; updated in 1999) ecological model of human interaction and human development provides a framework to understand the human interactions and experiences that cross social identity boundaries that lead to a broader conception of the self. Bronfenbrenner proposed that an individual's behavior (and ultimately, the internalization of that behavior into an integrated self) is a combination of the interactions within and across systems of influence. Microsystems represent close interactions with family and peers in defined groups (e.g., disciplinary peers). The next level of interactions, mesosystems, involve interactions between microsystems. For example, when two students form a study team because they are both enrolled in the same biology class and chemistry class. Exosystems, representing a further broadening of contexts, represent links across microsystems and mesosystems. An interdisciplinary STEM program that meets its interdisciplinary ideal and represents STEM as an integration of multiple disciplines represents engagement within the exosystem level. Macrosystems represent interactions that connect across lower-level systems, such as cultural values and norms. When students connect STEM projects with broader societal goals and values such as energy policy or environmental impact, the macrosystem is activated. The final system activated is the chronosystem, changes in the lower-level systems, and their interactions over time. For example, as government policy changes over time, an interdisciplinary STEM graduate may need to expand their research to address shifts in cultural values.

Data Science for Social Good (DSSG) provides an opportunity for students to move across systems and have interactions with others within broader systems of society. This movement across systems allows students to interact with STEM peers from different disciplines, work with faculty mentors that connect ideas across disciplines, address connections across fields of study, and work with STEM professionals who are addressing societal goals. These interactions help students develop complex experiences around the concept of STEM identity and allows them to interact with others who identify as STEM but who are not in their microsystems. Bronfenbrenner's (1999) ecological model has been used to explain adolescent identity development (Te'Neil Lloyd, 2002) as well as career identity development among women (Cook, Heppner, \& O'Brien, 2005). In the current manuscript, we explain the transformational shifts in STEM identity among students engaged in an interdisciplinary DSSG program.

\section{Personal Identity and Transformational Learning}

Transformational learning occurs through a process of experiential learning when there is a violation of expectations, the discovery of broader patterns that explain one's experience, and the resolution of cognitive tension through a reflection of suitable explanations for their new experience (Mezirow, 2000). Carter, Castano Rodriguez, and Jones (2014) advocate for implementing transformational learning in STEM education. The goal is to transform students' attitudes and agency through orienting students toward action with the science they study. Walker and Molnar (2013) illustrate how science education through experiential learning can shift high schoolers' identities as capable scientists through a transformational learning process. Aspects of personal identity development through transformational learning likely are relevant for college students as well. 
In the DSSG program, students face a complex set of educational experiences. Students face challenges related to their expertise, content knowledge, and personal roles within their discipline, and within the broader field of work, they plan to pursue after graduation. Students find opportunities for reflection on their experience and make meaning out of their interaction with others and with concepts in a context outside of the classroom (Mezirow, 2000). Within the context of adult education, Boyd and Myers (1988) outlined the development of student focus, from dealing with issues of ego and self-importance to socialfocused issues, where the student integrates their role and the role of others into their self-concept. According to Boyd and Myers, students experience a revised and more holistic view of their self-concept through a challenge, progressive skill development, and feedback from others. Within the concept of the ecological model of human development (Bronfenbrenner, 1999), students experience this challenge and skill development as they move across the micro-systems that tend to be more self-focused toward mesoand macro-systems that incorporate others into a holistic view of the self in relation to others.

\section{METHOD}

We are investigating STEM identity development among students enrolled in an interdisciplinary DSSG program. We conducted semi-structured interviews to determine what aspects of STEM identity might be affected as students participated and experienced an interdisciplinary STEM program where interactions with others outside their microsystem (i.e., their disciplinary context) was highly likely and encouraged.

\section{Approach}

We approach the understanding of this research from a social constructivist lens. Social constructivism assumes that humans make meaning, knowledge, and understanding via their experiences with others in social contexts interacting with their personal ideas. The praxis of meaning making is grounded in relativist ontological and subjectivist epistemological underpinnings (Lincoln \& Guba, 2000). That is, we contend that as students engage in the DSSG program, multiple realities are simultaneously constructed through the vantage points of individual participants. Furthermore, we view our understanding and interpretation of participants' STEM identity meaning making process as knowledge that is co-created. As we were interested in how students from interdisciplinary backgrounds come to make meaning of STEM identity through participation in a particular experience, case study was deemed an appropriate methodological choice. Our research incorporates aspects of three types of cases: intrinsic, instrumental, and descriptive (Stake, 2005). Our focus is on a particular interdisciplinary experience (DSSG) at one institution, and we seek to describe and understand how student participants come to construct (or re-construct) STEM identity.

\section{Site and Sampling}

Case study methodology requires defined contextual boundaries (Merriam \& Tisdell, 2016). Our case is bounded by time, location, and experience. A mid-sized public university in the southeast United States served as the site for a summer internship program (i.e., DSSG). The DSSG is a twelve-week experiential internship experience, where selected participants from different disciplines work together with non-profit organizations to address persistent social problems using data science solutions and provide data-driven decision-making recommendations. In 2013, Rayid Ghani from the University of Chicago developed a summer fellowship program named as Data Science for Social Good (DSSG) that trains computer scientists, statisticians, and social scientists from around the world to work on data science problems with social impact. Following the success of the DSSG program at Chicago, few other universities within the U.S. and Europe created their own DSSG summer internship programs. The program described in this article was started in 2017, independent of the Chicago program, while following the spirit of the DSSG. The southeast DSSG program was formed to address the data science solution needs of the nonprofits in the region as well as address the data scientist training demands of the university constituents. The DSSG program solicits project proposals from regional nonprofit organizations describing their social problems and relevant data. Intern positions are advertised to all colleges within the university. In the intern applications, 
students describe relevant project experiences and courses taken. Nonprofits and interns are then selected based on the matching of project needs and data science skills. Recruited interns work on the university campus during June, July, and August months on the selected projects.

During the internship, DSSG interns are supervised by internship directors, who are two faculty members, one from the School of Computing and one from the Psychology department. Faculty from other colleges provide interns with domain knowledge required to work on the selected projects. Data scientist professionals provide industry best practices and assist with troubleshooting technical problems faced by the interns. Faculty and professionals meet with interns every two weeks. Interns meet with nonprofit clients regularly to get more information about the project and datasets as well as obtaining feedback on the data science solutions developed. At the end of the DSSG program, interns present the project findings in an open-to-public forum.

\section{Participants}

Participants were all students who were selected for the DSSG summer internship experience at a public 4-year university in the southern U.S. Students were recruited as interns representing a variety of disciplines from the host university as well as applicants from other universities. In 2017, recruited interns were pursuing majors in the fields of computer science, information science, and psychology. In 2018, recruited interns were pursuing degrees in data science, computer science, statistics, mathematics, psychology, anthropology, and public administration. Invitations were sent to all student interns who participated in the DSSG program across 2017 (with 5 interns) and 2018 (with 8 interns). Of the 13 participants in the program, 6 interns agreed to complete the semi-structured interviews. Table 1 provides pseudonyms for the students as well as their academic background and self-reported gender.

TABLE 1

PARTICIPANT INFORMATION

\begin{tabular}{llll}
\hline Participant Pseudonym & Degree & Major & Gender \\
\hline Rhea & M.S. & Psychology & Female \\
Kelsey & M.S. & Data Science & Female \\
Gillian & B.S. & Mathematics & Female \\
Brooke & M.S. & Psychology & Female \\
Darell & B.S. & Statistics & Male \\
Tara & M.S. & Psychology & Female \\
\hline
\end{tabular}

\section{Data Collection}

Data were derived from reflection assignments completed during the internship and interviews conducted after the internship was complete. For two of the participants, the interviews were conducted one year after the completion of the internship. For the remaining four participants, the interviews were conducted a few months following the completion of the internship.

During the scheduled time of the internship, students completed written reflections about their experiences. Reflection questions were informed by transformational learning theory (Mezirow, 2000) and reflective judgment (King \& Kitchener, 1994). The reflection prompts asked students to address their frames of reference, to consider their goals and aspirations, and to consider the value in the perspectives of others in a consensus building framework. Students also reflected on what surprised them and what challenged them most, to address the limitations of their existing knowledge and to understand how others and different perspectives would contribute to the system of understanding the problem. The reflection questions were as follows:

- What inspired you to apply for the DSSG program?

- In what ways does the DSSG program support your career plans and aspirations? 
- Based on your interactions thus far, what is the value of working with Community Partners on a Social Good project?

- Based on your interactions thus far, what is the value of working with others from different disciplines?

- What are your personal and professional goals in participating in the DSSG Program?

- At this point, what has surprised or challenged you the most regarding the DSSG program and the work associated with the program?

In addition to these formal reflection prompts, students engaged in numerous opportunities for informal dialogue and reflection through meetings with the community partners, mentors, and faculty project leads. These reflections supported the approach of challenging students' existing knowledge frame and connecting them with others through collaborative dialogue and problem solving.

At the conclusion of their internship process, students participated in semi-structured, one-on-one interviews. Interviewees were provided the opportunity to interview face-to-face or by telephone, if distance limited availability for face-to-face participation. All interns from the 2017 and 2018 summer cohorts were sent an email from the DSSG faculty leads soliciting their participation in the interview. Those who agreed to participate were connected to a third faculty member who conducted the interviews. The faculty interviewer was not involved with the DSSG project during the first year of the summer internship, and served as a content area consultant for the second group of interns during their DSSG experience. Interviews were arranged at a time of mutual convenience for the participants and interviewer and lasted between 45 60 minutes in length. The interview protocol consisted of questions designed to have students reflect on the ecological systems and relational aspects of their DSSG experience and the impacts on their STEM identity. For example, one question asked, what was it like to work with others in disciplines different from yours? The full interview protocol is included in appendix A. All data were digitally audio recorded and transcribed for analysis.

\section{Data Analysis}

Once transcripts were available for all data, we proceeded with data analysis. Consistent with Case Study approaches, we utilized the constant comparative method as described by Glaser and Strauss (1967). First, we read through transcripts identifying initial codes, a process known as open coding. After initial open codes were identified, we re-read transcripts grouping open codes together into axial codes or groups of related codes. Finally, the axial code groups were collapsed into overarching themes that described consensual emergent ideas regarding the process of STEM identity development (Creswell \& Poth, 2018). Through the constant comparative process, three major themes emerged. Once these themes were established through analysis of the interview data, we integrated additional data from the formalized student written reflections and the informal written communications (e.g., communications with faculty and community partners). The data from these reflections were considered and compared to the themes that emerged through analysis from the interviews, and in this case, served to confirm the emergent themes.

\section{Trustworthiness and Credibility}

Several strategies were employed to ensure that our data were trustworthy or valid (Creswell \& Poth, 2018). First, data were triangulated using multiple sources of data as well as multiple researchers. Triangulation involves the process of corroboration of evidence via multiple data. Investigator triangulation allows for the perspectives of multiple researchers to validate emergent themes (Denzin, 1978). Additionally, our data and analysis were rich and thick in nature (Lincoln \& Guba, 1985). We also engaged collaboratively with our participants through the process and followed up regarding the appropriateness of the emergent themes as reflective of their experience, a process described as member checking (Creswell $\&$ Poth, 2018). Finally, we shared themes with faculty peers who engage in similar types of work, but who were not involved in this process, to confirm the credibility of our themes. 


\section{FINDINGS}

Analysis of our findings revealed three major themes that depict how the DSSG internship process informed participant's perspectives of self and ways of understanding STEM. These three overarching themes are (a) challenges to expectations of program and of self, (b) shift in personal perspectives and confidence, and (c) shift in ways of understanding STEM. These findings are explored in more detail here.

\section{Challenges to Expectations of Program and of Self}

Participants described their expectations and motivations for pursuing the program in different ways. For example, several participants shared they thought that the internship would provide the opportunity to hone or gain new statistical or technical skills that they could use to market themselves for a job or Ph.D. program. Others mentioned expecting to benefit from forming relationships with mentors. A few students whose disciplinary background was in a STEM field already felt comfortable with their computer or mathematical modeling skills, and mentioned connecting to the social good aspect of the internship, expecting to learn how to use their skill set to communicate with and impact others. For example, Gillian, a math major, shared,

the thing that really stood out to me about DSSG was the social good aspect...it was a way to use my math skills in a way that would impact people.... lot of people pushed me in the computer science direction [saying] 'you should write code for a website and make a bunch of money'

The students coming from STEM backgrounds tended to enter the internship program with the expectation that they would have much to contribute to the group. As Darell, a data scientist, explained, "I was pretty skilled when it came to like making algorithms, developing, like certain models...I was expecting to be around a bunch of people that got their degree in computer science." Gillain shared her initial expectations,

it was me, um, getting a math degree...there was one girl from anthropology, two girls from psychology, and someone from public health...in all honesty, when I walked into the internship, I was thinking like...what could they, like not in a mean way, but I was like 'What could they possibly contribute coming from those?

With a background in psychology, Brooke detailed her initial trepidation with becoming a part of the DSSG program, "I was really scared as a Psych major of like not being able to add anything because I feel like there's a stigma in psychology where we don't know more stuff than other people, that we tend to be a softer science". Regardless of discipline, all participants talked about not expecting the group to be interdisciplinary. For example, Tara commented, "So I went in not knowing it would be so multidisciplinary. So when I realized there were so many different disciplines it was, that was a shock." Realizing the interdisciplinary nature of the group led to questions regarding the ease of communication between group members. Tara went on to explain one of her biggest challenges through the internship was,

when we had issues communicating...maybe I described something that I thought [group members] would understand, but then i get something back that was completely the opposite...so we would run into some communication issues where I thought I thought I was describing something, but the terms I used meant something else in their discipline.

Kelsey described a similar situation, "Well, it took me a bit to realize we were talking about the data in different ways. [Group members from different disciplines] didn't understand why I was like asking the questions I was asking." Communication was brought up by participants in various ways. While some, like Tara and Kelsey, talked about not expecting to face challenges regarding communicating with group 
members, others including Darell and Rhea expected that the internship opportunity would help them hone their communication and presentation skills. Darell said, "I was considering to get better at being able to talk better in front of audiences...I was expecting, like being able to talk data...I wanted to be able to communicate everything." On the other hand, Kelsey experienced challenges regarding communication with community partners. She explained that initially, she anticipated communication with community partners to be one of her strengths, but found the process to be more challenging than she initially expected. In Kelsey's words,

the communication piece, I just didn't expect it to be as complicated as it was...honestly I thought I was going to be fine communicating even with clients...I think that's why I was so like frustrated because I didn't anticipate... [communicating to the client] was something I really struggled with in this internship."

In addition to expectations regarding communication, several participants talked about the challenges they faced regarding their community partner's data. Darell, a data scientist, worked on a project where the data was not numerical in nature - a drastic departure from the types of data that he was used to working with. Darell described this challenge,

I went into expecting, like I kind of got this, this is science, [but] the fact that one of my clients that we did have, didn't have any data. I was like, 'this is kinda giving me anxiety'...I guess that [was a] surprising fact there.

Kelsey, also a data scientist, expressed frustration with her community partner's data, "like ok, I don't know what I'm supposed to do with this data...like we don't have the data to do what you're asking us to do." As participants detailed the challenges they faced regarding their expectations of the program and for themselves, they also described how they negotiated these challenges. This process created space for shifts in their personal perspectives and growth in their confidence - the second emergent theme of this study.

\section{Shift in Personal Perspectives and Confidence}

In their own ways, participants described how the internship process led to shifts in their personal perspectives and confidence levels. For instance, several participants, including Darell and Rhea, talked about how they gained increased confidence in their communication and presentation skills via the DSSG experience. Darell shared that he considered increased communication and presentation skills to be one of the most valuable take-aways from the program,

Like for me personally, help me talk data and like be able to present very well in front of like audiences and like I've been doing that...we've been going into pitch competitions and like I've been pitching these people and every time, they're just like, 'how'd you learn to speak so well?', and I'm like 'Oh, I did this internship a summer ago'.

Another participant, Rhea shared Darell's perspective,

I also learned more of how to present data in a very easy and I guess kind of forgiving way to individuals that are trying to digest your data, so doing it in a way that's understandable to your audience....also my presentation skills, um, improved drastically just, um, learning how to speak properly and clearly and articulately in front of a large audience.

Some participants shared that while they initially doubted how they might be able to contribute, they quickly came to feel confident and appreciation for their personal value add to the projects. Brooke reflected on her experience sharing how her perspective regarding her contribution changed, 
when I realized like [psychologists] had knowledge and insight that like the other people didn't. And they had insight to like things we didn't think of in the saw way, that was a huge deal I think during it is just how useful [psychology] is and how useful my skills actually are because I didn't really think they were that useful outside of actual psychology before this.

Similarly, Tara shared, "so shifting from being really scared about having no idea what I'm doing to kind of being more confident, cause it's like, okay." Kelsey also underestimated her value-add to the group. She shared that, even though she was coming from a data science background, she initially questioned if her technical skills were advanced enough for contribution, but came to realize that she was more proficient than she gave herself credit for.

I was really nervous that I wasn't going to be as good...I knew I had gaps in my understanding about the whole data science process, so there was some nervousness like, 'Am I gonna have the coding skills? Am I gonna have the statistics skills?...[as the internship progressed] I was like, 'Oh my gosh, um the thing that I questioned the most was like my value in terms of like the technical skills'.

As participants reflected on their experiences in the DSSG program, they started to reveal not only a shift in their personal perspectives and confidence, but also new and more nuanced understandings of the meaning of STEM learning. This third and final theme is explored here.

\section{Shift in Ways of Understanding STEM}

Through their participation in the DSSG internship, participants revealed how their perspectives regarding the way they understood STEM shifted, both for those who were from traditionally accepted STEM backgrounds, and also for those who were not. With her math background, Gillian had always considered herself to be a part of STEM, but talked about how her perspective of what STEM is shifted through the internship. When asked if her concept of STEM changed throughout the program, She shared that she now considered STEM to be "creative" and "innovative and wanting to, like, change things positively." In Gillian's words,

Yeah, absolutely, I think it goes back to the whole data science is for everybody kind of idea...When I first started studying, um, I kind of just thought that, you know, like STEM is like the hard sciences...its rigorous, and it's rigid, and there are rules to it...this internship, I think, kind of helped me see where you can loosen up and like, not break the rules, but just bend, kind of, the rigidity a little bit, things become a little more free-flowing... a lot can come into it and they can be much more creative, I think, than what I used to see STEM as.

Gillian was only one of several participants who described her broadened understanding of STEM learning. As Darell recounted his frustration regarding his perception of the lack of data of his community partner, he also shared how he relied upon his teammate to help him make a positive impact for them,

[Teammate] is an anthropology major and she actually like, she had a very interesting opinion on just like the main cause of what we're doing. She definitely like help gear it into a different direction. Like, me, I was just thinking data, data, data, algorithms, algorithms, algorithms, but she was just like, 'Okay, so like what's beyond that? Like what problem are we actually trying to solve? What are we actually trying to help these nonprofits do?' 
Brooke expanded upon this idea by explaining how her view of STEM learning had broadened through her experience,

I think STEM is kind of like the hub of what trans-relational research should be. It is taking the understanding of our world, the natural world and understanding of people and being able to take all that information from STEM and give it back to the world.

Brooke went on to describe how, as a psychologist, her personal connection to STEM shifted through the DSSG program.

Going to an engineering school where they were like hard, hard scientists and they didn't consider psychology a STEM area really, they barely considered biology a STEM area. And so I kind of lost that connection with STEM for a while because I didn't feel like I had enough skill or enough like ability to be a part of that. And the DSSG really brought me back to understanding that STEM is a lot broader than what, you know, hard scientists might think sometimes, in that, I do have a purpose in that.

Rhea also described STEM as collaborative and interdisciplinary, "having the social sciences at the table with computer science, I think you just have a much richer picture of what you're trying to figure out than just having one person at the table." When asked if she felt she was a part of STEM, she responded,

I would say maybe like logistically no because there is nothing attached to my name that says STEM. But more conceptually I would say yes, because I am heavily involved with science. Um, and I do collaborative work with other people within other fields of science. So I would say yes, but I think, I'm not sure STEM is fully inclusive of what it necessarily intended if that makes sense.

Taken together, these findings provide insight into the change process for students who were involved in the DSSG internship experience. In the discussion section below, we more deeply explore the meaning of these findings and provide recommendations for practice and policy.

\section{DISCUSSION}

This research was designed to understand how participation in an interdisciplinary experiential learning internship affected students' STEM identity. The findings from the study revealed that regardless of their disciplinary background students began the internship experience with pre-formed expectations regarding their understanding of what STEM was, who they regarded as a part of STEM, and of themselves as STEMcapable. As the internship progressed, students were met with challenges that disrupted their initial expectations, and in turn, resulted in a rethinking of the nature of STEM learning and their conception of who could, and should, be included in the data analytics problem solving previously reserved for those in STEM disciplines. In other words, as they were challenged through the internship experience, their initial understandings of STEM changed, their definitions of STEM broadened, and they were more easily able to view themselves and/or those from disciplines not traditionally defined as STEM as STEM-capable.

These interpretations are validated from theoretical perspectives. Carlone and Johnson's (2007) theory of science identity describes the building of a science identity as an interactive process, whereby individuals must demonstrate competence as a scientist, and that performance must be recognized by credible established individuals within the scientific community. From this perspective, the transformation of students that occurred during the DSSG internship regarding students' conceptual understanding of STEM, and consequently their STEM identities, may have been, in part, attributed the internship opportunities to demonstrate their competence, and also to receive validation from peers, faculty, and community partners. 
Furthermore, in our initial approach to framing this research, we utilized Bronfenbrenner's (1999) ecological systems model. Bronfenbrenner posited that human development occurs as individuals move across the more self-focused microsystems into the meso- and macro-systems where they see themselves in relation to broader contexts. This perspective allows for one plausible interpretation of these findings. That is, through increased connections to those from interdisciplinary contexts and also with community partners, students were experiencing a move away from their micro-systems (i.e., those in their immediate circles or discipline) and into the broader meso- and - macro systems. The experience of collective critical thinking and problem solving with others from interdisciplinary backgrounds (i.e., other student interns and faculty mentors) perspectives facilitated new ways of viewing the self as part of a larger broader system. Moreover, the interactions with the community partners served as a catalyst for connections between the self and social good.

From these perspectives both Carlone and Johnson's (2007) science identity model and Bronfenbrenner's ecological systems model allowed us to better understand how interactions collaborating on STEM-related problem solving with others outside of one's discipline could theoretically help to transform perceptions of what STEM is and who is STEM-capable. However, both of these models treat identity development as a static, or one-way growth process, that encourages movement away from one space and into another. For instance, as a student grows their science identity, they would leave behind old beliefs that they did not belong in the science community. In the ecological systems model, individuals move away from the self-focused micro-systems into the broader context systems. Our findings point towards a more complex representation of the transformative experience. That is, the students in this research described a process whereby they were growing stronger in their confidence and beliefs about belonging in both their discipline, but also in STEM. Using their experiences as examples, this research may demonstrate the need to reconceptualize and redefine STEM learning in more inclusive ways. In a study out of the University of California, Los Angeles, Herrera, Hurtado, Garcia, and Gasiewski (2005) call for redefining STEM for graduate students. Their approach models how STEM can be more inclusive for those with various social identities. We extend this line of thinking, to include those from different disciplinary backgrounds.

\section{Implications and Recommendations}

Findings from this study have broad reaching implications for practice and policy. Evidence from this work suggests that through the process of participation in DSSG, an example of an experiential interdisciplinary summer internship program, students from differing disciplinary backgrounds shifted their perceptions of themselves and others as STEM-capable. Increased numbers and support for programs such as DSSG, that provide the opportunity for interdisciplinary thought and collaboration to solve big, complex problems should be prioritized on college and university campuses. Furthermore, it is recommended that colleges and universities, or granting agencies consider funding or further support a centralized center for interdisciplinary projects. A supportive infrastructure that encourages interdisciplinary experiential student opportunities may also stimulate faculty interest and involvement in such programs. Lastly, hiring agencies may benefit from the findings of this study. Understanding how participation in an interdisciplinary experiential program shifts perspectives of students may facilitate more informed hiring practices and better student job placement and fit.

\section{CONCLUSION}

This research describes a transformative process of STEM identity development that occurs when students from different disciplinary backgrounds face challenges to their expectations regarding themselves and others as STEM-capable. Increasing numbers of STEM-capable individuals who are equipped to tackle 21 st century problems will require more intentionally designed educational experiences that allow students to engage with others in and out of their discipline. We posit that interdisciplinary opportunities provide space for students to challenge their predefined beliefs regarding belonging in the STEM community. 


\section{REFERENCES}

Berman, F., Rutenbar, R., Christensen, H., Davidson, S., Estrin, D., Franklin, M., . . Szalay, A. (2018). Realizing the potential of data science. Communications of ACM, 61(4), 67-72.

Boyd, R.D., \& Myers, J.G. (1988). Transformative education. International Journal of Lifelong Education, 7(4), 261-284.

Bronfenbrenner, U. (1977). Toward an experimental ecology of human development. American Psychologist, 32, 513-531.

Bronfenbrenner, U. (1999). Environments in developmental perspective: Theoretical and operational models. In S.L. Friedman \& T.D. Wachs (Eds.), Measuring environment across the life span: Emerging methods and concepts (pp. 3-28). Washington, DC: American Psychological Association.

Burkam, D.T., Lee, V.E., \& Smerdon, B.A. (1997). Gender and science learning early in high school: Subject matter and laboratory experiences. American Educational Research Journal, 34(2), 297331.

Carlone, H.B., \& Johnson, A. (2007). Understanding the science experiences of successful women of color: Science identity as an analytic lens. Journal of Research in Science Teaching: The Official Journal of the National Association for Research in Science Teaching, 44(8), 1187-1218.

Carter, L., Castano Rodriguez, C., \& Jones, M. (2014). Transformative Learning in Science Education: Investigating Pedagogy for Action. In J. Bencze \& S. Alsop (Eds.), Activist Science and Technology Education. Cultural Studies of Science Education (Vol. 9). Springer, Dordrecht.

Cook, E.P., Heppner, M.J., \& O’Brien, K.M. (2005). Multicultural and gender influences in women's career development: An ecological perspective. Journal of Multicultural Counseling and Development, 33(3), 165-179.

Creswell, J.W., \& Poth, C.N. (2018). Qualitative inquiry and research design: Choosing among five approaches. Sage publications.

Denzin, N.K. (1978). Sociological methods: A sourcebook. New York, NY: McGraw-Hill.

Giffi, C.A., Dollar, B., Wellener, P., Manolian, H.A., Monck, L. \& Moutray, C. (2018). The jobs are here, but where are the people? Retrieved January 14, 2020, from

https://www2.deloitte.com/us/en/insights/industry/manufacturing/manufacturing-skills-gapstudy.html

Glaser, B.G., \& Strauss, A.L. (1967). The Discovery of Grounded Theory: Strategies for Qualitative Research. New York: Aldine De Gruyter.

Graf, N., Fry, R., \& Funk, C. (2018). 7 facts about the STEM workforce. Retrieved January 14, 2020, from https:/www.pewresearch.org/fact-tank/2018/01/09/7-facts-about-the-stem-workforce/

Griffith, A.L. (2010). Persistence of women and minorities in STEM field majors: Is it the school that matters? Economics of Education Review, 29(6), 911-922.

http://doi.org/10.1016/j.econedurev.2010.06.010

Herrera, F.A., Hurtado, S., Garcia, G.A., \& Gasiewski, J. (2012). A model for redefining STEM identity for talented STEM graduate students. In American Educational Research Association Annual Conference.

King, P.M., \& Kitchener, K.S. (1994). Developing Reflective Judgment: Understanding and Promoting Intellectual Growth and Critical Thinking in Adolescents and Adults. Jossey-Bass Higher and Adult Education Series and Jossey-Bass Social and Behavioral Science Series. Jossey-Bass, San Francisco, CA.

Landivar, L.C. (2013). Disparities in STEM employment by sex, race, and Hispanic origin. Retrieved January 14, 2020, from https://www.census.gov/library/publications/2013/acs/acs-24.html

Lee, V.E., \& Burkam, D.T. (1992). Transferring high schools: An alternative to dropping out? American Journal of Education, 100, 420-453. 
Ley, C., \& Bordas, S.P.A. (2018). What makes data science different? A discussion involving statistics 2.0 and computational sciences. International Journal of Data Science and Analytics, 6(3), 167175. https://doi.org/10.1007/s41060-017-0090-x

Lincoln, Y.S., \& Guba, E.G. (1985). Naturalistic Inquiry. Thousand Oaks: SAGE Publications.

Lincoln, Y.S., \& Guba, E.G. (2000). Paradigmatic controversies, contradictions, and emerging confluences. In N.K. Denzin \& Y.S. Lincoln (Eds.), Handbook of qualitative research (2nd ed., pp. 163-188). Thousand Oaks, CA: Sage.

Markus, H., \& Kunda, Z. (1986). Stability and malleability of the self-concept. Journal of Personality and Social Psychology, 51, 858-866.

Mayes, R., Rittschof, K., Gallant, B., \& Martin, C. (2017). Real STEM: An interdisciplinary STEM program. Journal of Research in STEM Education, 3(1/2), 1-16.

Merriam, S., \& Tisdell, E.J. (2016). Qualitative research: A guide to design and implementation (4th ed.). San Francisco, CA: Jossey-Bass.

Mezirow, J. (2000). Learning to think like an adult. In J. Mezirow, Learning as transformation: Critical perspectives on a theory in progress (pp. 3-33). Josey Bass; San Francisco, CA.

NSF. (2015). Revisiting the STEM Workforce: A Companion to Science and Engineering Indicators 2014. National Science Foundation. Retrieved January 14, 2020, from https://www.nsf.gov/pubs/2015/nsb201510/nsb201510.pdf

Stake, R.E. (2005). Qualitative Case Studies. In N.K. Denzin \& Y.S. Lincoln (Eds.), The Sage Handbook of Qualitative Research (pp. 443-466). Sage Publications Ltd.

Te'Neil Lloyd, B. (2002). A conceptual framework for examining adolescent identity, media influence, and social development. Review of General Psychology, 6(1), 73-91.

Walker, T., \& Molnar, T. (2013). Can experiences of authentic scientific inquiry result in transformational learning? Journal of Transformative Education, 11(4), 229-245.

Whitehouse-NSTC. (2018). Charting a course for success: America's strategy for STEM education. Retrieved January 14, 2020, from https://www.whitehouse.gov/wpcontent/uploads/2018/12/STEM-Education-Strategic-Plan-2018.pdf

\section{APPENDIX}

\section{Interview Protocol}

1. Tell me about how you decided to apply for the internship program?

a. What factors did you consider in this process?

2. What are the most important things you learned throughout the program?

a. How about what you learned about yourself through the process?

3. What was it like to work with others in disciplines different from your yours?

a. Were there elements that surprised you? Elements that challenged you?

4. Who did you rely on for support during the internship?

a. Were there different people who provided different types of support to you?

b. What did that look like?

5. What challenges did you face through the program and how did you work through them?

6. What did you feel your role was in the data science group?

a. Did those roles shift throughout the program?

7. What do you view as the purpose of the internship program?

a. How did you connect with this purpose?

b. Did that change throughout the program?

8. Is there anything else I did not ask that you would like to share about your experience? 